\title{
Purkinje cell loss by OX7-saporin impairs acquisition and extinction of eyeblink conditioning
}

\author{
Brian C. Nolan and John H. Freeman ${ }^{1}$ \\ Department of Psychology, University of lowa, lowa City, lowa 52242, USA
}

\begin{abstract}
The current study examined the effects of globally depleting Purkinje cells in the cerebellar cortex with the immunotoxin OX7-saporin on acquisition and extinction of delay eyeblink conditioning in rats. Rats were given OX7-saporin or saline $2 \mathrm{wk}$ before the start of eyeblink conditioning. The rats that reached a performance criterion of two consecutive days with $80 \%$ or greater conditioned responses were given $5 \mathrm{~d}$ of extinction training followed by $2 \mathrm{~d}$ of reacquisition training. Rats that received infusions of OX7-saporin had 77.2\%-97.9\% Purkinje cell loss and exhibited impaired acquisition and extinction. The amount of Purkinje cell loss was correlated with the magnitude of the acquisition and extinction impairments. The highest correlations between Purkinje cell number and the rate of acquisition were in lobule HVI and the anterior lobe. The highest negative correlation between Purkinje cell number and the percentage of conditioned responses during extinction was in the anterior lobe. The results indicate that cerebellar Purkinje cells, particularly in the anterior lobe and lobule HVI, play significant roles in acquisition and extinction of eyeblink conditioning.
\end{abstract}

Cerebellar learning is critical for making adaptive adjustments to movements. An early model of cerebellar learning proposed by Albus (1971) suggests that learning-specific changes in synaptic function occur exclusively in the cerebellar cortex. Empirical evidence supporting learning-specific changes in cerebellar cortex initially came from neurophysiological analyses of arm movements and adaptation of the vestibular ocular reflex (Ito 1972; Gilbert and Thach 1977; Ito and Kano 1982). Evidence subsequently emerged that indicated a critical role for learning-specific plasticity in the cerebellar and vestibular nuclei (Miles and Lisberger 1981; McCormick and Thompson 1984a,b). The most prevalent view currently is that learning-specific plasticity occurs in the cerebellar cortex and deep nuclei (Mauk and Donegan 1997; Steinmetz 2000; Christian and Thompson 2003). The computational model of Mauk and colleagues further specifies that plasticity in the cerebellar cortex is critical for initial acquisition and timing of conditioned responses, whereas plasticity in the interpositus nucleus is necessary for long-term storage of a basic (not precisely timed) conditioned response (CR) (Medina et al. 2001; Ohyama and Mauk 2001).

The precise role of the cerebellar cortex in eyeblink conditioning has been difficult to establish, due primarily to discrepant findings between laboratories. Some laboratories found that cortical lesions abolished eyeblink CRs, while others found recoverable deficits, depending on lesion size, location, and amount of pre-lesion training (McCormick and Thompson 1984a; Yeo et al. 1985; Lavond et al. 1987; Lavond and Steinmetz 1989; Yeo and Hardiman 1992; Harvey et al. 1993; Perrett et al. 1993; Woodruff-Pak et al. 1993). Moreover, Yeo and colleagues demonstrated that reversible inactivation of cortical activity in HVI and the anterior lobe abolished CRs, blocked acquisition, and impaired consolidation (Attwell et al. 1999, 2001, 2002). Christian and Thompson (2004), however, did not impair consolidation of eyeblink conditioning with post-training inactivation of the cerebellar cortex. The results of lesion and inactivation studies indicate that the cerebellar cortex plays an important

\section{'Corresponding author.}

E-mail john-freeman@uiowa.edu; fax (319) 335-0191.

Article and publication are at http://www.learnmem.org/cgi/doi/10.1101/ Im.168506. role in acquisition and retention of eyeblink conditioning, but do not collectively demonstrate how much of the memory underlying the eyeblink CR resides in the cortex.

Neurophysiological studies of cerebellar cortical plasticity during eyeblink conditioning revealed learning-specific activity that emerged as CRs were acquired and persisted during overtraining (McCormick et al. 1982; McCormick and Thompson 1984b; Berthier and Moore 1986; Gould and Steinmetz 1994, 1996; Hesslow and Ivarsson 1994; Green and Steinmetz 2005). Single unit analyses of Purkinje cell activity have shown conditioning-specific increases and decreases in simple spike activity (Berthier and Moore 1986; Hesslow and Ivarsson 1994; Gould and Steinmetz 1996; Green and Steinmetz 2005). A large proportion of Purkinje cells in the anterior lobe and lobule HVI showed either increased or decreased simple spike activity during training, but a subset showed an initial increase in activity during the conditioned stimulus (CS) followed by a decrease toward the end of the stimulus, when CRs occurred (Hesslow and Ivarsson 1994; Green and Steinmetz 2005). Learning-specific changes in Purkinje cell activity are thought to shape the topography of the CR by inhibiting eyelid movement early in the CS period and releasing inhibition later in the CS period (Medina et al. 2000; Green and Steinmetz 2005). Intracellular recordings from Purkinje cell dendrites in lobule HVI indicate a learning-specific increase in membrane excitability (Schreurs et al. 1991, 1997, 1998), which could be a mechanism underlying increases in learning-related simple spike activity seen in the unit recording studies.

The interpretation of findings from lesion and neurophysiological studies is complicated by the demonstration of multiple blink zones within the cerebellar cortex (Hesslow 1994). Lesions, for example, could fail to abolish CRs or block acquisition if they did not destroy all of the blink zones in the cortex. Three approaches have been used to produce global impairments in cerebellar cortical function during eyeblink conditioning that would presumably affect more of the blink zones: pharmacological disconnection of the cortex, Purkinje cell degeneration (pcd) mice, and Purkinje cell destruction with OX7-saporin. GABA antagonists have been used to reversibly disconnect the cortex from the deep nuclei (Mamounas et al. 1987; Garcia and Mauk 1998; Medina et al. 2001; Bao et al. 2002; Aksenov et al. 2003). Pharmacological disconnection of the cerebellar cortex produces dis- 
ruption of CR timing and resistance to extinction (Mamounas et al. 1987; Garcia and Mauk 1998; Medina et al. 2001). CR performance and timing are impaired by sequential administration of the GABA agonist muscimol and the GABA antagonist picrotoxin, which disconnects the cerebellar cortex from the nuclei while preventing membrane depolarization that occurs with picrotoxin alone (Bao et al. 2002). A limitation of the pharmacological method is that it only disconnects cortical areas in the injected hemisphere that project to the targeted nucleus (i.e., the interpositus nucleus). Additional blink zones within the ipsilateral hemisphere, vermis, or contralateral hemisphere could contribute to CR acquisition or extinction. A more global effect on cerebellar cortical function is found in pcd mice. Mice with this spontaneous mutation lose almost all of their Purkinje cells within the first postnatal month. These mice show impaired acquisition of eyeblink conditioning, but they do exhibit significant conditioning and extinction (Chen et al. 1996, 1999).

Another approach to producing global effects on cerebellar cortical function is to deplete Purkinje cells throughout the cortex in adult animals with the immunotoxin OX7-saporin (Nolan and Freeman Jr. 2005). OX7-saporin selectively kills Purkinje cells when infused into the ventricles (Davis and Wiley 1989; Waite et al. 1999; Angner et al. 2000; Gandhi et al. 2000; Wrenn and Wiley 2001; Nolan and Freeman Jr. 2005). One advantage of using OX7-saporin relative to pcd mice is that pcd mice lose Purkinje cells during postnatal brain development, which could result in compensatory changes in the deep nuclei and brain stem (Freeman Jr. et al. 1995), whereas OX7-saporin can be administered to adult animals. A previous study found that rats given OX7-saporin after eyeblink conditioning showed an initial loss of CRs and a deficit in reacquisition (Nolan and Freeman Jr. 2005).

The current experiment examined the effects of globally depleting Purkinje cells with OX7-saporin on acquisition and extinction of eyeblink conditioning. It was predicted that rats in the OX7-saporin group would be more impaired on acquisition and extinction than pcd mice or animals with more focal cerebellar cortical lesions. The rats given OX7-saporin were expected to be more impaired than pcd mice because the toxin was administered to adult rats and there would, therefore, be less opportunity for developmental compensation relative to pcd mice. OX7-saporin administration depletes Purkinje cells throughout the cortex, presumably affecting all of the blink zones, which would result in more severe deficits than observed following focal lesions that destroy only a subset of the cortical blink zones. Rats were given OX7-saporin or saline two weeks before the start

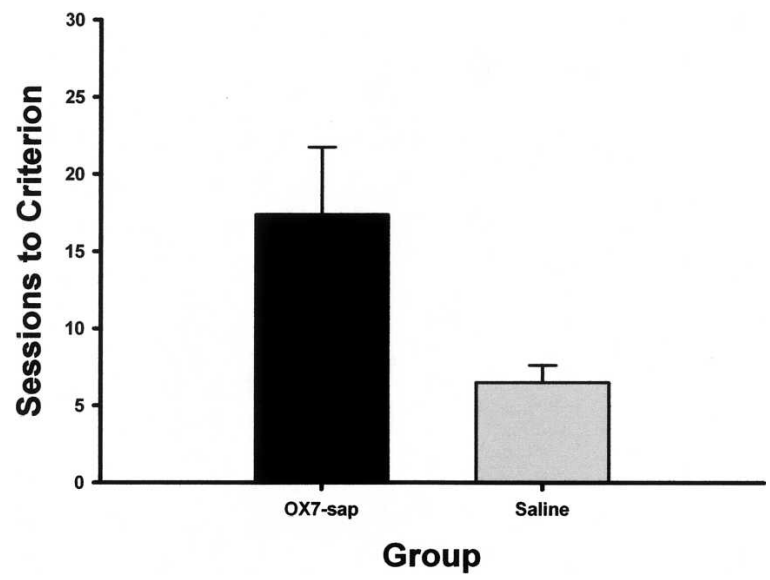

Figure 1. Mean (+SEM) sessions to acquisition criterion for the OX7saporin (black) and saline (gray) groups.

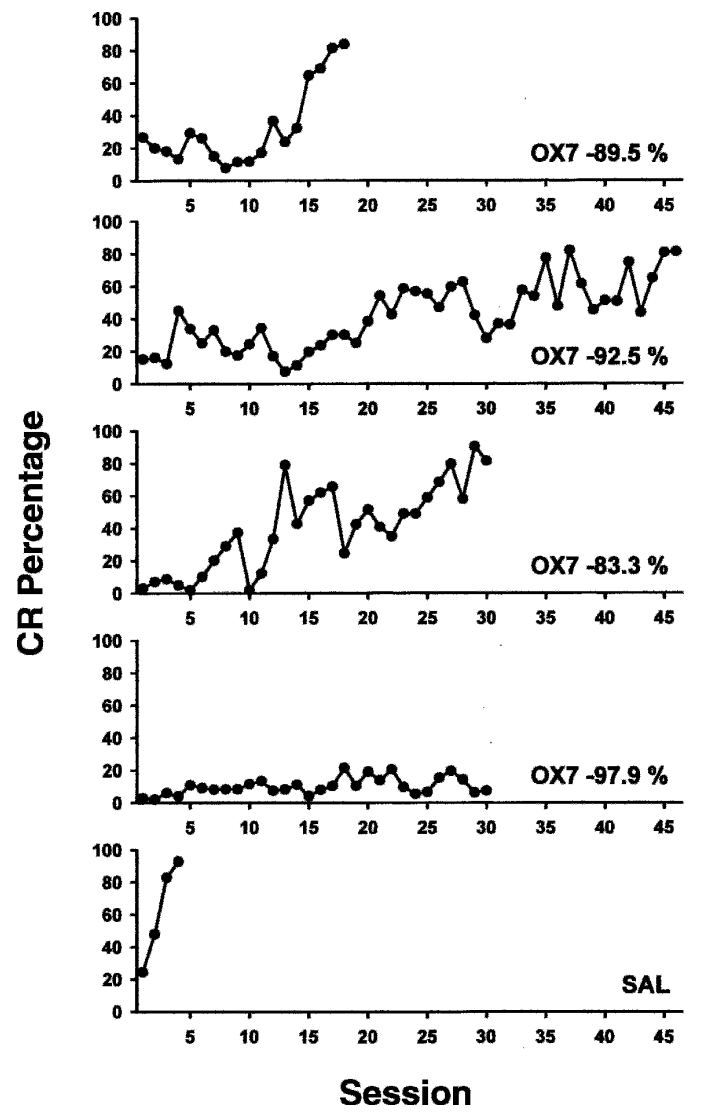

Figure 2. Percentage of CRs during 100-trial sessions of acquisition training for four rats that were given OX7-saporin (top four rows) and one saline control (bottom row). The percentage of Purkinje cell loss in the anterior lobe is indicated for each rat.

of delay eyeblink conditioning. The rats were trained until reaching a criterion of two consecutive sessions with $80 \%$ or greater CRs. They were then given five sessions of extinction training followed by two reacquisition sessions.

\section{Results}

\section{Acquisition and extinction}

Acquisition of eyeblink conditioning was impaired by Purkinje cell depletion with OX7-saporin. A $t$-test revealed a significant group difference in the number of sessions to reach the acquisition criterion $\left(t_{[18]}=2.42, P<0.03\right)$, indicating that the rats that received OX7-saporin took significantly longer to acquire excitatory conditioning relative to the control group (Fig. 1). Figure 2 shows the CR percentage across training sessions for four severely impaired rats treated with OX7-saporin (percentage of Purkinje cell loss indicated) and a representative saline control. The most severely impaired rats had the most Purkinje cell loss (see Regression analysis below), one of which showed no evidence of conditioning after 3000 trials (Fig. 2, 4th row). Analyses were also performed on CR onset latency, peak latency, and amplitude. There were no significant group differences for these measures (onset: $t_{[18]}=0.23, P=0.824$; peak: $t_{[18]}=0.25, P=0.808$; CR amplitude: $t_{[18]}=1.27, P=0.221$; Fig. 3 ). Figure 4 shows the CR onset latency across training sessions for the rats that were used in Figure 2.

Extinction was also impaired in the group given OX7saporin (Fig. 5). A repeated measures ANOVA indicated a significant group effect $\left(F_{[1,16]}=11.76, P<0.004\right)$ and a significant ef- 


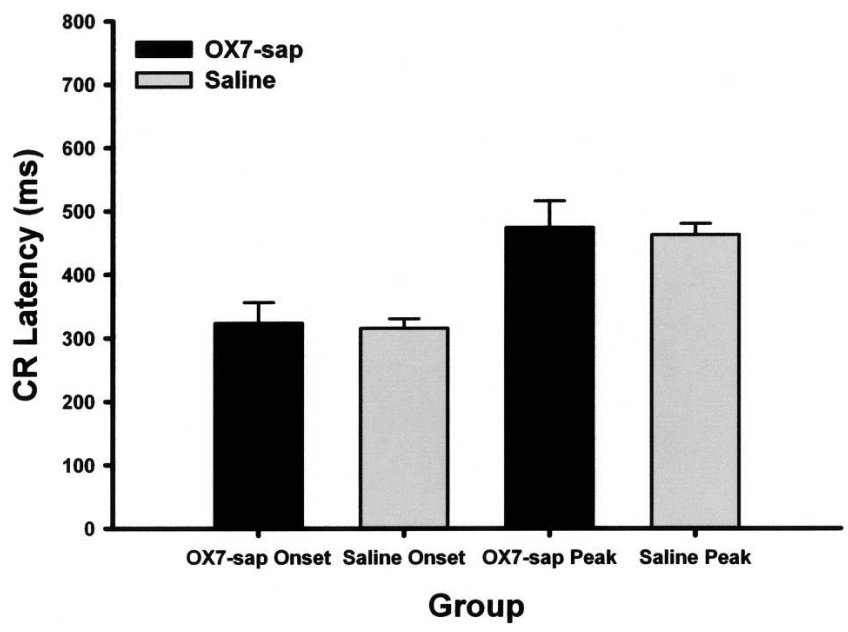

Figure 3. Mean (+SEM) conditioned response (CR) onset latency and CR peak latency for the OX7-saporin (black) and saline (gray) groups on the last day of acquisition training.

fect of the session factor $\left(F_{[4,64]}=5.20, P<0.002\right)$, but no interaction of the group and session factors $\left(F_{[4,64]}=1.62, P=0.180\right)$. The group effect resulted from a higher percentage of CRs in the OX7-saporin group relative to the saline group during the five extinction sessions. The session effect resulted from both groups showing a decrease in CR percentage across the five sessions. A repeated measures ANOVA of the CR percentage data from reacquisition indicated no significant effect of the group factor $\left(F_{[1,16]}=0.50, P=0.488\right)$, no interaction of the group and session factors $\left(F_{[1,16]}=0.58, P=0.328\right)$, but a significant effect of the session factor $\left(F_{[1,16]}=8.68, P<0.01\right)$. The significant effect of the session factor was due to an increase in the percentage CRs from the first session to the second session in both groups.

\section{Histology}

Purkinje cell and interpositus nucleus cell counts were performed as described below for all OX7-saporin rats with accurate cannula placements (regardless of whether they successfully completed training) and six of the saline rats. $t$-tests revealed significant group differences for the whole section counts $\left(t_{[17]}=14.29\right.$, $P<0.001)$, lobule HVI counts $\left(t_{[17]}=8.00, P<0.001\right)$, and anterior lobe counts $\left(t_{[17]}=23.14, P<0.001\right)$, but not for the interpositus counts $\left(t_{[17]}=1.20, P=0.245\right)$. Figure 6 shows high (upper) and low (lower) magnification views of the Purkinje cell layer in lobule HVI from a saline and a moderately affected OX7saporin rat. Figure 7 shows the mean Purkinje cell counts for the whole cerebellum, lobule HVI, anterior lobe, and interpositus nucleus.

A potential concern regarding the use of OX7-saporin is that there may be damage to extracerebellar structures within the eyeblink conditioning circuitry. As in our previous OX7-saporin study, there was a moderate loss of cells in the inferior olive (Nolan and Freeman Jr. 2005). Moderate cell loss in the inferior olive associated with Purkinje cell depletion is also seen following cerebellar cortical lesions (Yeo et al. 1985; Lavond et al. 1987; Harvey et al. 1993; Woodruff-Pak et al. 1993) and in pcd mice (Chen et al. 1996, 1999). Other parts of the eyeblink conditioning circuitry including the cochlear nuclei, pontine nuclei, red nucleus, and facial motor nucleus appeared to be unaffected by OX7-saporin (Nolan and Freeman Jr. 2005).

\section{Regression analysis}

There was a significant amount of variability in the behavioral measures and the Purkinje cell counts for the OX7-saporin group.
It was, therefore, possible that there would be linear relationships between the extent of Purkinje cell loss and measures of behavioral performance. A previous study found a correlation between the number of Purkinje cells and the rate of learning in rabbits (Woodruff-Pak et al. 1990). In order to look for such a trend in the current study, a series of regression analyses was performed. Relationships between Purkinje cell counts (whole cerebellum, lobule HVI, and anterior lobe) and the behavioral measures (sessions to criterion, CR onset latency, CR peak latency, and CR amplitude) were examined. Table 1 summarizes the $F$-value, $P$ value, and Pearson's $r$ for each relationship. A negative correlation between the number of Purkinje cells and the number of sessions to criterion was evident for HVI and marginally significant for the anterior lobe $(P=0.051)$. The number of Purkinje cells in HVI was positively correlated with CR amplitude. Scatter plots with the regression line for Purkinje cell counts in HVI and CR percentage and CR amplitude are shown in Figure 8. There were no significant relationships between any of the other variable pairs during acquisition. The percentage of CRs during extinction was negatively correlated with the number of Purkinje cells in the anterior lobe and whole cerebellar samples.

Ataxia scores were compared to Purkinje cell counts and measures of CR performance. For the Purkinje cell counts, the ataxia scores showed a significant linear relationship with the whole section count $\left(F_{[1,17]}=32.102, P<0.000\right)$, HVI count $\left(F_{[1,17]}=31.508, P<0.000\right)$, and the anterior lobe count $\left(F_{[1,17]}=39.997, P<0.000\right)$. For the CR performance measures, the only significant linear relationship with the ataxia score was

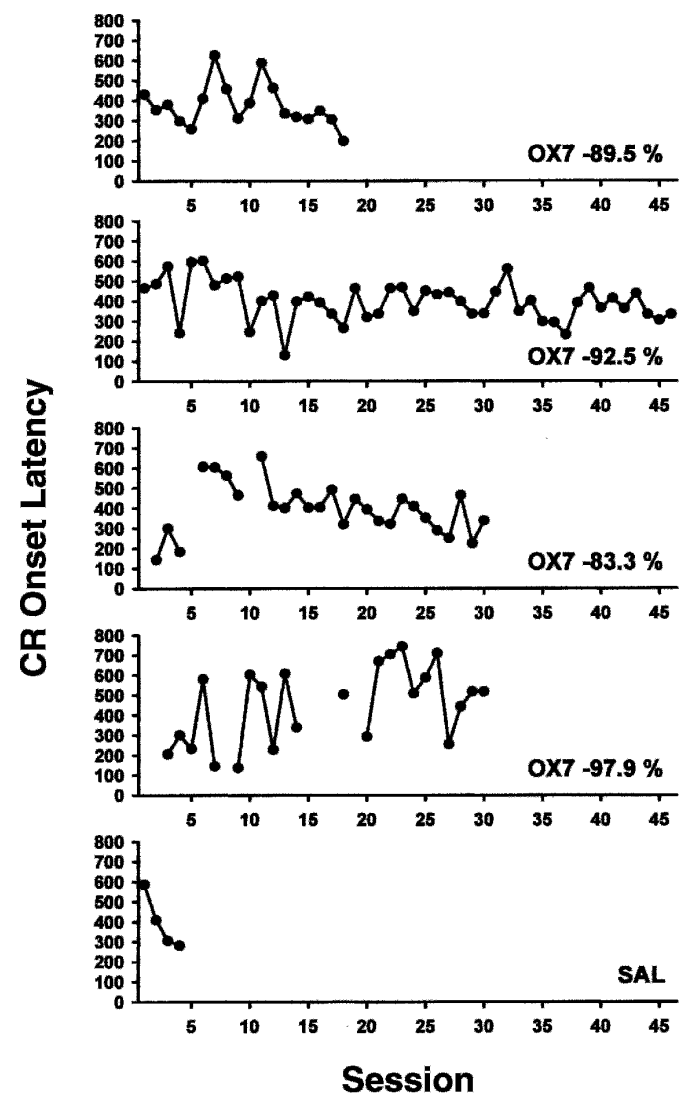

Figure 4. Conditioned response (CR) onset latency during 100-trial sessions of acquisition training for four rats that were given OX7-saporin (top four rows) and one saline control (bottom row). The percentage of Purkinje cell loss in the anterior lobe is indicated for each rat. Breaks in the data lines indicate sessions with no CRs. 


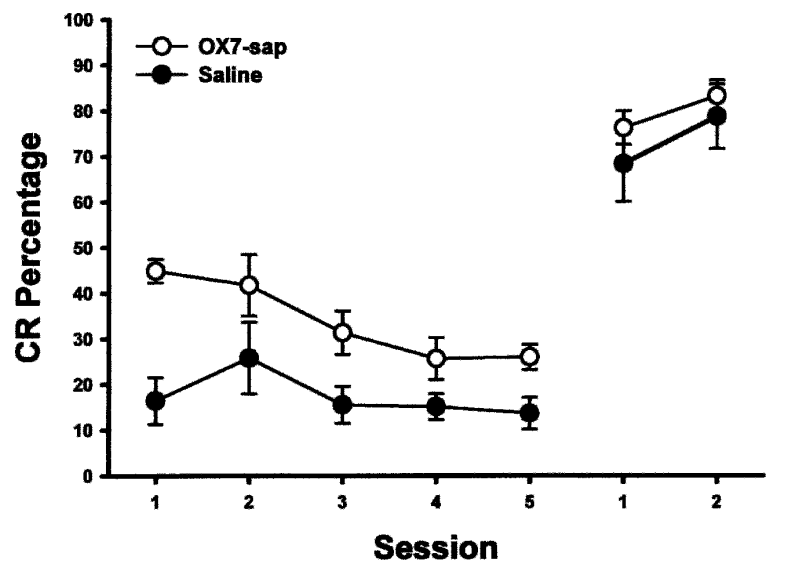

Figure 5. Mean $( \pm$ SEM) conditioned response (CR) percentage for the OX7-saporin (white) and saline (black) groups across five 100-trial sessions of extinction (left) and two 100-trial sessions of reacquisition training (right).

with sessions to criterion during acquisition $\left(F_{[1,17]}=7.806\right.$, $P<0.02)$.

\section{Discussion}

Rats that received intraventricular infusions of OX7-saporin prior to training showed deficits in acquisition and extinction of delay eyeblink conditioning. The rats with the most Purkinje cell depletion were severely impaired during acquisition training and one of these rats failed to show any evidence of conditioning, even after extensive training. The rats with Purkinje cell depletion also showed impaired extinction. The extent of Purkinje cell loss was correlated with the behavioral impairments. The highest correlation between Purkinje cell number and the rate of acquisition was seen in lobule HVI. There was also a linear relationship between the number of Purkinje cells in the anterior lobe and rate of acquisition. The highest negative correlation between Purkinje cell number and the percentage of CRs during extinction was in the anterior lobe. The Purkinje cell counts in the anterior lobe and lobule HVI were highly correlated (0.904), indicating that both areas play significant roles in acquisition and extinction.

The behavioral effects observed after OX7-saporin-induced Purkinje cell loss are similar to behavioral impairments observed in Purkinje cell degeneration (pcd) mutant mice (Chen et al. 1996, 1999). In the Chen et al. (1996) study, pcd mice and wildtype mice were trained on delay conditioning for 10 sessions followed by 4 sessions of extinction training. The pcd mice were significantly impaired in excitatory acquisition, achieving $~ 40 \%$ CRs by the 10 th session versus $\sim 70 \%$ CRs in the wild-type mice. No significant group difference was found in CR onset latency, but CR peak latency was reduced in the pcd mice. Since training was stopped after 10 sessions, it is not known whether the pcd mice would achieve CR percentages similar to those in the wildtype mice if given additional training. The slower acquisition rate and lack of an effect on CR onset latency are consistent with the current data. However, the previously observed effect on CR peak latency is not consistent with the current data nor with our previous OX7-saporin study (Nolan and Freeman Jr. 2005), which may be due to species differences or neural reorganization that occurs in the pcd mice following Purkinje cell loss during development (Freeman Jr. et al. 1995). The most severely impaired rats in the current study showed a larger impairment during the first 10 training sessions than the pcd mice (Fig. 2). However, to thor- oughly compare the two effects, pcd mice and mice given OX7saporin should be compared directly using the same procedures.

One of the advantages of using OX7-saporin and pcd mice is that Purkinje cells throughout the cerebellum are destroyed, which avoids the potential problem that localized lesions could miss a region that is important for eyeblink conditioning. However, an examination of the pattern of Purkinje cell loss in the OX7-saporin rats revealed that the degree of loss was not consistent across the cerebellum. The degree of cell loss was greater in the distal ends of the folia. The greatest concentration of Purkinje cells remaining was consistently deep in the folds of the folia. The pattern of cell loss can be accounted for by considering the route of drug administration, through the CSF that surrounds the cerebellum. The drug would, therefore, have more tissue to penetrate to reach the more central portions of the cerebellum. Another trend was that the anterior lobe consistently demonstrated a greater proportion of Purkinje cell loss than other regions of the cerebellum. This finding is consistent with studies that have implicated the anterior lobe in acquisition of eyeblink conditioning (Perrett et al. 1993; Garcia et al. 1999; Green and Steinmetz 2005). The current data are also consistent with studies that implicate lobule HVI in eyeblink conditioning (Yeo et al. 1985; Lavond et al. 1987; Yeo and Hardiman 1992; Attwell et al. 1999, 2001, 2002). The findings of the current study, therefore, suggest that the anterior lobe and lobule HVI are primary contributors to the acquisition of eyeblink conditioning in rats.

Extinction of eyeblink conditioning is thought to depend on new learning in the cerebellar cortex that is induced by CSrelated activity in parallel fibers in the absence of climbing fiber activity (Perrett and Mauk 1995; Medina et al. 2002; Mauk and Ohyama 2004). Repeated parallel fiber stimulation in the absence of climbing fiber stimulation leads to long-term potentiation of parallel synapses with Purkinje cells. The development of longterm potentiation during CS-alone trials in extinction would produce stronger inhibition of the deep nuclei during CS presentations and thereby inhibit performance of CRs. Support for this view comes from simulations and experiments that used lesions
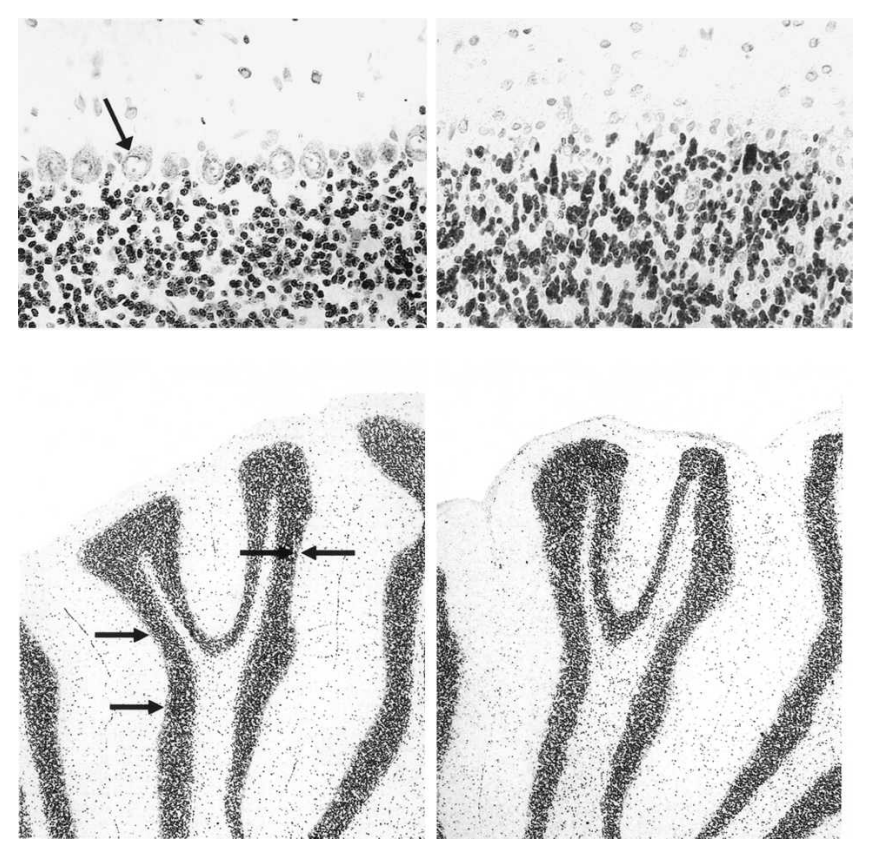

Figure 6. Images of the cerebellar cortex showing the Purkinje cell layer in a rat infused with saline (left) and a rat infused with OX7-saporin (right) at $40 \times$ (upper) and $5 \times($ lower) magnifications. Arrows indicate the location of the Purkinje cell layer. 

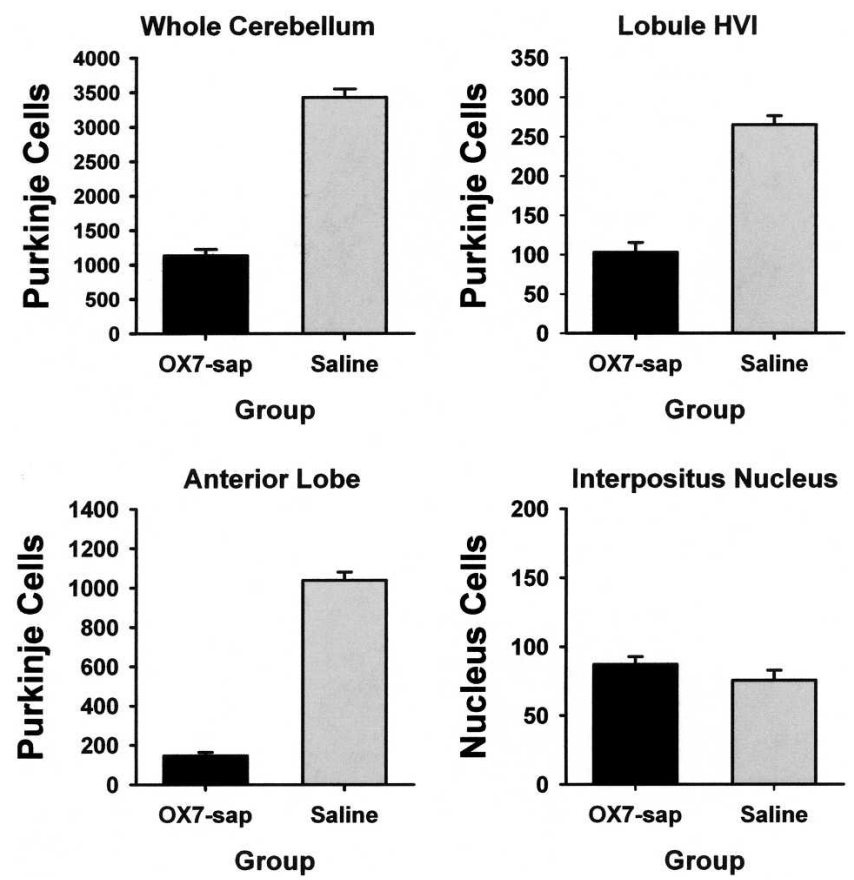

Figure 7. Mean (+SEM) number of Purkinje cells from samples of the whole cerebellum (upper left), lobule HVI (upper right), anterior lobe (lower left), and interpositus nucleus cells (lower right) for the OX7-saporin (black) and saline (gray) groups.

or pharmacological disconnection of the cerebellar cortex from the deep nuclei during extinction training (Medina et al. 2001, 2002; Mauk and Ohyama 2004). Disconnection of the cortex with picrotoxin produces a substantial resistance to extinction. According to simulations of extinction, it requires a reduction in climbing fiber activity below an equilibrium level, which induces long-term potentiation to CS-related inputs to Purkinje cells (Medina et al. 2002). Blockade of GABAergic inhibition of the inferior olive increases the rate of climbing fiber activity above the hypothetical equilibrium level and impairs extinction (Medina et al. 2002). The deficit in extinction observed in the rats with Purkinje cell loss following OX7-saporin treatment is consistent with the proposed model of extinction. Other mechanisms involved in extinction of eyeblink conditioning including contributions of the hippocampus, and feedback from motor and sensory nuclei in the brain stem (Robleto et al. 2004) may have their effects on CR inhibition by influencing Purkinje cells' synaptic plasticity.

In conclusion, depletion of Purkinje cells throughout the cerebellar cortex impaired acquisition and extinction of eyeblink conditioning. The impairments are generally consistent with models of cerebellar learning that posit a role for Purkinje cell synaptic plasticity in new learning, which includes de novo acquisition and extinction. However, rats with nearly complete loss of Purkinje cells eventually acquired high levels of performance, suggesting that other neural systems such as the interpositus nucleus can slowly establish conditioning.

\section{Materials and Methods}

\section{Subjects}

Subjects were 20 adult male Long-Evans rats (250 g-350 g). The rats were housed in the animal colony in Spence Laboratories of Psychology at the University of Iowa. They were given free access to food and water and kept on a 12-h light/12-h dark cycle. All procedures were approved by the Institutional Animal Care and Use Committee at the University of Iowa.

\section{Surgery and recovery}

Surgery was performed 2 wk prior to training. Each rat was anesthetized with an i.p. injection of sodium pentobarbital $(60 \mathrm{mg} /$ $\mathrm{kg})$ and atropine sulfate $(0.67 \mathrm{mg} / \mathrm{kg})$. After the onset of anesthesia, the rat was placed in a stereotaxic apparatus. A 30-gauge guide cannula was lowered into the left lateral ventricle. The stereotaxic coordinates for the cannula tip relative to bregma were $1.2 \mathrm{~mm}$ posterior, $1.5 \mathrm{~mm}$ lateral, and $4.0 \mathrm{~mm}$ ventral to the skull surface. OX7-saporin (Advanced Targeting Systems) or PBS was then infused at $25 \mu \mathrm{L} / \mathrm{h}(15.0 \mu \mathrm{g})$. After the infusion, the cannula remained in place for an additional $15 \mathrm{~min}$ before removal. Differential EMG electrodes were then implanted in the left upper eyelid muscle (orbicularis oculi) with a ground wire attached to a skull screw. The two EMG wires and ground wire were attached to a small plastic connector with gold pins. A bipolar stimulating electrode (Plastics One) was implanted subdermally caudal to the left eye for delivery of the shock unconditioned stimulus. The bipolar electrode was attached to a plastic connector. All components were then cemented in place with dental acrylic and sutures were made as necessary. The rats were given post-surgical injections of ketoprofen $(5 \mathrm{mg} / \mathrm{kg})$ for analgesia and monitored until recovery from anesthesia was evident.

During the recovery period, the rats were monitored daily for signs of ataxia and possible weight loss. When weight loss occurred, supplementing their diet with moistened food (dry rat chow pellets soaked in water overnight) placed on a small glass tray in the cage was sufficient to maintain body weight. Ataxia was assessed using a subjective rating that ranged from a score of 0 (no ataxia, normal gait and posture) to 7 (very severe ataxia, unable to walk or maintain upright posture).

\section{Training apparatus}

The conditioning apparatus consisted of four small-animal sound attenuation chambers (BRS/LVE). Within each sound attenuation chamber was a small-animal operant chamber (BRS/ LVE), which was fitted with two speakers and a small light. The sound attenuation chambers also contained a mounted fan that produced background noise ( $\sim 65 \mathrm{~dB})$.

The plugs on the rat's head stage were connected to lightweight cables and a commutator. The cables were connected to peripheral equipment for recording EMG activity and delivering stimuli. The EMG signal was recorded differentially, filtered $(500-5000 \mathrm{~Hz})$, amplified $(2000 \times)$, integrated, and then input to a computer where it was recorded and displayed by custom software (JSA Designs). The JSA software controlled the delivery of the stimuli (tone and shock). The shock stimulus (2-3 mA, DC)

Table 1. Regression analysis and Pearson's $r$ for Purkinje cell count numbers versus the behavioral measures

\begin{tabular}{clrrr}
\hline & Variables & F-value & P-value & Pearson's $\boldsymbol{r}$ \\
\hline Whole section & Sessions to criterion & 3.638 & 0.077 & -0.454 \\
count & CR onset latency & 0.195 & 0.666 & -0.117 \\
& CR peak latency & 0.032 & 0.861 & -0.047 \\
& CR amplitude & 3.543 & 0.081 & 0.449 \\
Lobule HVI & CR \% extinction & 4.949 & $0.044^{\mathrm{a}}$ & -0.525 \\
count & Sessions to criterion & 5.150 & $0.040^{\mathrm{a}}$ & -0.519 \\
& CR onset latency & 0.769 & 0.395 & -0.228 \\
& CR peak latency & 0.161 & 0.694 & -0.107 \\
Anterior lobe & CR amplitude & 6.106 & $0.027^{\mathrm{a}}$ & 0.551 \\
count & CR \% extinction & 2.400 & 0.145 & -0.395 \\
& Sessions to criterion & 4.535 & $0.051^{\mathrm{a}}$ & -0.495 \\
& CR onset latency & 0.320 & 0.580 & -0.150 \\
& CR peak latency & 0.249 & 0.625 & -0.132 \\
& CR amplitude & 1.912 & 0.188 & 0.347 \\
& CR \% extinction & 5.351 & $0.038^{\mathrm{a}}$ & -0.540 \\
\hline
\end{tabular}

${ }^{a}$ Indicates statistical significance. 

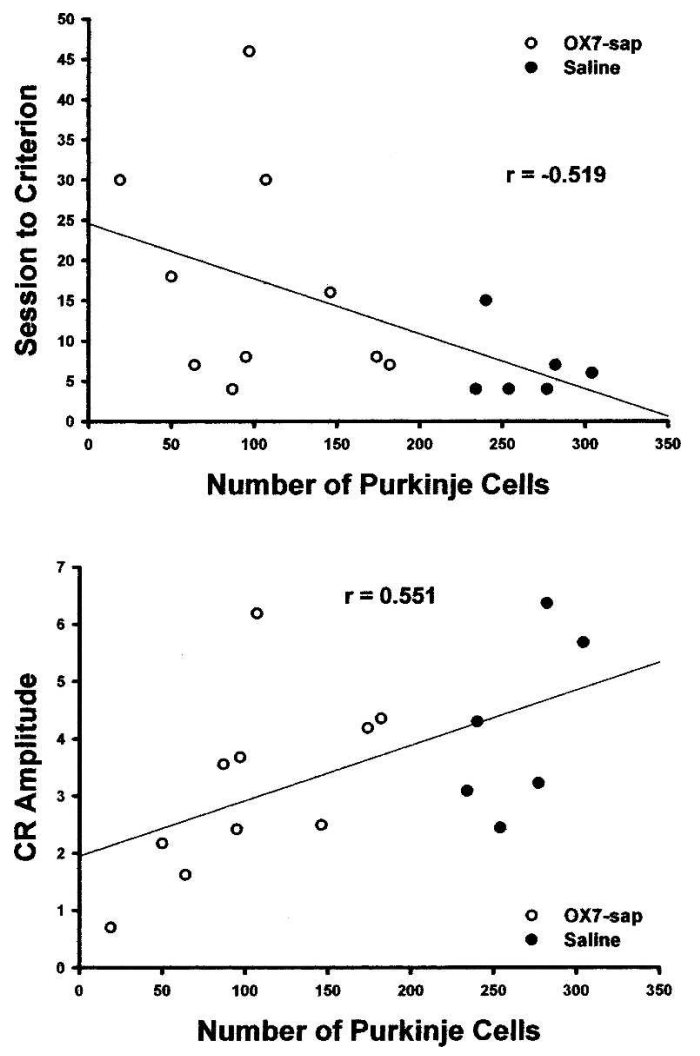

Figure 8. Plots of the number of sessions to criterion (upper) and conditioned response (CR) amplitude (lower) versus the Purkinje cell counts in lobule HVI for OX7-saporin (white circles) and saline (black circles) groups with regression line shown.

was produced by a stimulus isolator (model 365A World Precision Instruments).

\section{Training procedure}

Training sessions were performed once daily and consisted of 100 trials. The CS used was a $500-\mathrm{ms}$ tone $(2 \mathrm{kHz}, 85 \mathrm{~dB})$ and the unconditioned stimulus (US) was a periorbital shock delivered during the last $25 \mathrm{msec}$ of the CS period. The average intertrial interval was $30 \mathrm{sec}$ (ranging from 20 to $40 \mathrm{sec}$ ). Training consisted of three phases: acquisition, extinction, and reacquisition. The acquisition phase involved paired training $(2-\mathrm{kHz}$ tone paired with shock) until a performance criterion of $80 \%$ CRs for two consecutive sessions was reached. Paired training sessions included 10 blocks of trials, each block consisting of 9 CS-US paired trials and $1 \mathrm{CS}$-alone trial. Extinction training involved presenting the CS alone for five 100-trial sessions. Extinction was only examined in rats that reached the acquisition criterion. As a result, the OX7-saporin and saline groups started extinction training from the same level of performance. Reacquisition consisted of two additional sessions of paired training.

If a rat failed to reach at least $50 \%$ CRs by session 30 , training was terminated (only one subject fit this category). Rats that attained $50 \%$ CRs or greater by session 30 continued training for a maximum of 50 sessions.

\section{Histology}

The histological methods were the same as used in a previous study (Nolan and Freeman Jr. 2005). After completion of training, the rats were euthanized with an injection of sodium pentobarbital $(120 \mathrm{mg} / \mathrm{kg})$ and transcardially perfused with physiological saline followed by $3 \%$ formaldehyde. The brains were removed and the forebrains were placed in 10\% sucrose dissolved in PBS and allowed to soak for at least $24 \mathrm{~h}$. Using a microtome, $50-\mu \mathrm{m}$ horizontal sections of the forebrain were prepared. The sections were then stained with cresyl violet. Sections were inspected under a light microscope to confirm that the cannula was placed in the left lateral ventricle.

The cerebellum of each rat was embedded in paraffin. A rotary microtome was used to cut 5 - $\mu$ m horizontal sections, and every section was mounted on gelatin-coated slides. The sections were then stained with cresyl violet as described above. Slices were examined under a light microscope, and representative horizontal sections of the cerebellum were selected at three different levels (from bregma, DV $-5.7 \mathrm{~mm},-5.0 \mathrm{~mm},-4.4 \mathrm{~mm}$ ). The first section $(-5.7 \mathrm{~mm})$ was used for obtaining cell counts of the interpositus nucleus. The other two sections were used for obtaining Purkinje cell counts. The $-5.0-\mathrm{mm}$ section was defined by the anatomical marker at the dorsal tip of the fastigial nucleus. The $-4.4-\mathrm{mm}$ section was defined by the anatomical marker at the point where white matter is no longer visible in lobule III. At each of these levels $(-5.0 \mathrm{~mm}$ and $-4.4 \mathrm{~mm})$ Purkinje cells were counted through the whole section, lobule HVI, and the anterior lobe by an investigator who was not aware of which experimental group the samples were drawn from. The Purkinje cell counts from each of these two levels were combined for subsequent analyses. Purkinje cells were counted using a manual clicker with a $40 \times$ objective. Cells were included in the count if they were stained neuronal cell bodies of sufficient size and in the appropriate location to be considered Purkinje cells.

A different counting technique was used to assess the number of neurons in the interpositus nucleus. Light microscope photographs were taken of the interpositus nucleus of each subject at equivalent anatomical levels, as mentioned above, defined by the DV level where the dorsal tip of the dentate nucleus is barely visible. The images were processed using Image J software. The images were trimmed so they only included the interpositus nucleus. Then a threshold analysis was applied that only kept the objects of sufficient darkness in the field of view (Image J). Finally, a count was performed by the program, which counted any object larger than 150 pixels.

\section{Data analysis}

The behavioral data were examined for each training session. A $t$-test was used to analyze a possible group difference in the number of sessions to reach the acquisition criterion. Repeated measures ANOVA was performed for the CR percentage, CR amplitude, CR onset latency, and CR peak latency data from the extinction and reacquisition phases because equal numbers of sessions were given to the treatment groups. The CR amplitude, $\mathrm{CR}$ onset latency, and CR peak latency were taken from CS-alone trials (10 per session) in which a response occurred during the 500-ms CS or up to $300 \mathrm{~ms}$ after CS offset (800-ms sampling period). The CR amplitude and latency data were taken from the last training session to ensure that there were a sufficient number of CS-alone trials in both groups to perform meaningful parametric statistical comparisons. Measures of CR performance were highly variable during earlier sessions in the OX7-saporin group (see Fig. 4) due to the low frequency of CRs. The CR amplitude and latency analyses should, therefore, be considered as assessments of CR performance, not measures of CR acquisition.

Linear relationships between the number of Purkinje cells (whole section, lobule HVI, and anterior lobe) and behavioral performance (sessions to criterion, CR onset latency, CR peak latency, and CR amplitude) were examined with regression analysis (Nolan and Freeman Jr. 2005).

\section{Acknowledgments}

This work was supported by NIMH grant MH065483 to J.H.F.

\section{References}

Aksenov, D., Serdyukova, N., Irwin, K., and Bracha, V. 2003. GABA neurotransmission in the cerebellar interposed nuclei: Involvement in classically conditioned eyeblinks and neuronal activity. $J$. Neurophysiol. 91: 719-727.

Albus, J.S. 1971. A theory of cerebellar function. Math. Biosci. 10: 25-61. 
Angner, R.T., Kelly, R.M., Wiley, R.G., Walsh, T.J., and Reuhl, K.R. 2000. Preferential destruction of cerebellar Purkinje cells by OX7-saporin. Neurotoxicology 21: 395-404.

Attwell, P.J.E., Rahman, S., Ivarsson, M., and Yeo, C.H. 1999. Cerebellar cortical AMPA-kainate receptor blockade prevents performance of classically conditioned nictitating membrane responses. J. Neurosci. 19: RC45, 1-6.

Attwell, P.J.E., Rahman, S., and Yeo, C.H. 2001. Acquisition of eyeblink conditioning is critically dependent on normal function in cerebellar cortical lobule HVI. J. Neurosci. 21: 5715-5722.

Attwell, P.J.E., Cooke, S.F., and Yeo, C.H. 2002. Cerebellar function in consolidation of a motor memory. Neuron 34: 1011-1020.

Bao, S., Chen, L., Kim, J.J., and Thompson, R.F. 2002. Cerebellar cortical inhibition and classical eyeblink conditioning. Proc. Natl. Acad. Sci. 99: 1592-1597.

Berthier, N.E. and Moore, J.W. 1986. Cerebellar Purkinje cell activity related to the classically conditioned nictitating membrane response. Exp. Brain Res. 63: 341-350.

Chen, L., Bao, S., Lockard, J.M., Kim, J.J., and Thompson, R.F. 1996. Impaired classical eyeblink conditioning in cerebellar-lesioned and Purkinje cell-degeneration (pcd) mutant mice. J. Neurosci. 16: $2829-2838$.

Chen, L., Bao, S., and Thompson, R.F. 1999. Bilateral lesions of the interpositus nucleus completely prevent eyeblink conditioning in Purkinje cell-degeneration mutant mice. Behav. Neurosci. 113: $204-210$

Christian, K.M. and Thompson, R.F. 2003. Neural substrates of eyeblink conditioning: Acquisition and retention. Learn. Mem. 10: 427-455.

- 2004. Consolidation of the associative memory formed during classical eyeblink conditioning. Abstract Viewer/Itinerary Planner, Program No. 325.5. Society for Neuroscience, Washington, D.C.

Davis, T.L. and Wiley, R.G. 1989. Anti-thy-1 immunotoxin, OX7-saporin, destroys cerebellar Purkinje cells after intraventricular injection in rats. Brain Res. 504: 216-222.

Freeman Jr., J.H., Carter, C.S., and Stanton, M.E. 1995. Early cerebellar lesions impair eyeblink conditioning in developing rats: Differential effects of unilateral lesions on postnatal day 10 or 20. Behav. Neurosci. 109: 893-902.

Gandhi, C.C., Kelly, R.M., Wiley, R.G., and Walsh, T.J. 2000. Impaired acquisition of a Morris Water Maze task following selective destruction of Purkinje cells with OX7-saporin. Behav. Brain Res. 109: 37-47.

Garcia, K.S. and Mauk, M.D. 1998. Pharmacological analysis of cerebellar contributions to the timing and expression of conditioned eyelid responses. Neuropharmacology 37: 471-480.

Garcia, K.S., Steele, P.M., and Mauk, M.D. 1999. Cerebellar cortex lesions prevent acquisition of conditioned eyelid responses. $J$. Neurosci. 19: 10940-10947.

Gilbert, P.F.C. and Thach, W.T. 1977. Purkinje cell activity during motor learning. Brain Res. 128: 309-328.

Gould, T.J. and Steinmetz, J.E. 1994. Multiple-unit activity from rabbit cerebellar cortex and interpositus nucleus during classical discrimination/reversal eyelid conditioning. Brain Res. 652: 98-106.

. 1996. Changes in rabbit cerebellar cortical and interpositus nucleus activity during acquisition, extinction, and backward classical conditioning. Neurobiol. Learn. Mem. 65: 17-34.

Green, J.T. and Steinmetz, J.E. 2005. Purkinje cell activity in the cerebellar anterior lobe after rabbit eyeblink conditioning. Learn. Mem. 12: 260-269.

Harvey, J.A., Welsh, J.P., Yeo, C.H., and Romano, A.G. 1993. Recoverable and nonrecoverable deficits in conditioned responses after cerebellar cortical lesions. J. Neurosci. 13: 1624-1635.

Hesslow, G. 1994. Correspondence between climbing fiber input and motor output in eyeblink-related areas in cat cerebellar cortex. $J$. Physiol. 476: 229-244.

Hesslow, G. and Ivarsson, M. 1994. Suppression of cerebellar Purkinje cells during conditioned responses in ferrets. Neuroreport 5: 649-652.

Ito, M. 1972. Neural design of the cerebellar motor control system. Brain Res. 40: $81-84$

Ito, M. and Kano, M. 1982. Long-lasting depression of parallel fiber-Purkinje cell transmission induced by conjunctive stimulation of parallel fibers and climbing fibers in the cerebellar cortex. Neurosci. Lett. 33: 253-258.

Lavond, D.G. and Steinmetz, J.E. 1989. Acquisition of classical conditioning without cerebellar cortex. Behav. Brain Res. 33: $113-164$.

Lavond, D.G., Steinmetz, J.E., Yokaitis, M.H., and Thompson, R.F. 1987. Reacquisition of classical conditioning after removal of cerebellar cortex. Exp. Brain Res. 67: 569-593.

Mamounas, L.A., Thompson, R.F., and Madden IV, J. 1987. Cerebellar
GABAergic processes: Evidence for critical involvement in a form of simple associative learning in the rabbit. Proc. Natl. Acad. Sci. 84: 2101-2105.

Mauk, M.D. and Donegan, N.H. 1997. A model of Pavlovian eyelid conditioning based on the synaptic organization of the cerebellum. Learn. Mem. 3: 130-158.

Mauk, M.D. and Ohyama, T. 2004. Extinction as new learning versus unlearning: Considerations from a computer simulation of the cerebellum. Learn. Mem. 11: 566-571.

McCormick, D.A. and Thompson, R.F. 1984a. Cerebellum: Essential involvement in the classically conditioned eyelid response. Science 223: $296-299$.

. 1984b. Neuronal responses of the rabbit cerebellum during acquisition and performance of a classically conditioned nictitating membrane-eyelid response. J. Neurosci. 11: 2811-2822.

McCormick, D.A., Clark, G.A., Lavond, D.G., and Thompson, R.F. 1982. Initial localization of the memory trace for a basic form of learning. Proc. Natl. Acad. Sci. 79: 2731-2735.

Medina, J.F., Garcia, K.S., Nores, W.L., Taylor, N.M., and Mauk, M.D. 2000. Timing mechanisms in the cerebellum: Testing prediction of a large-scale computer simulation. J. Neurosci. 20: 5516-5525.

Medina, J.F., Garcia, K.S., and Mauk, M.D. 2001. A mechanism for savings in the cerebellum. J. Neurosci. 21: 4081-4089.

Medina, J.F., Nores, W.L., and Mauk, M.D. 2002. Inhibition of climbing fibers is a signal for the extinction of conditioned eyelid responses. Nature 416: 330-333.

Miles, F.A. and Lisberger, S.G. 1981. Plasticity in the vestibule-ocular reflex: A new hypothesis. Annu. Rev. Neurosci. 4: 273-299.

Nolan, B.C. and Freeman Jr., J.H. 2005. Purkinje cell loss by OX7-saporin impairs excitatory and inhibitory eyeblink conditioning. Behav. Neurosci. 119: 190-201.

Ohyama, T. and Mauk, M.D. 2001. Latent acquisition of timed responses in cerebellar cortex. J. Neurosci. 21: 682-690.

Perrett, S.P. and Mauk, M.D. 1995. Extinction of conditioned eyelid responses requires the anterior lobe of the cerebellar cortex. $J$. Neurosci. 15: 2074-2080.

Perrett, S.P., Ruiz, B.P., and Mauk, M.D. 1993. Cerebellar cortex lesions disrupt learning- dependent timing of conditioned eyelid responses. J. Neurosci. 13: 1708-1718.

Robleto, K., Poulos, A.M., and Thompson, R.F. 2004. Brain mechanisms of extinction of the classically conditioned eyeblink response. Learn. Mem. 11: 517-524.

Schreurs, B.G., Sanchez-Andres, J.V., and Alkon, D.L. 1991. Learning-specific differences in Purkinje cell dendrites of lobule HVI (lobulus simplex): Intracellular recording in a rabbit cerebellar slice. Brain Res. 548: $18-22$.

Schreurs, B.G., Tomsic, D., Gusev, P.V., and Alkon, D.L. 1997. Dendritic excitability microzones and occluded long-term depression after classical conditioning of the rabbit's nictitating membrane response. J. Neurophysiol. 77: 86-92.

Schreurs, B.G., Gusev, P.A., Tomsic, D., Alkon, D.L., and Shi, T. 1998 Intracellular correlates of acquisition and long-term memory of classical conditioning in Purkinje cell dendrites in slices of rabbit cerebellar lobule HVI. J. Neurosci. 18: 5498-5507.

Steinmetz, J.E. 2000. Brain substrates of classical eyeblink conditioning: A highly localized but also distributed system. Behav. Brain Res. 110: $13-24$.

Waite, J.J., Wardlow, M.L., and Power, A.E. 1999. Deficit in selective and divided attention associated with cholinergic basal forebrain immunotoxic lesion produced by 192-saporin; motoric/sensory deficit associated with Purkinje cell immunotoxic lesion produced by OX7-saporin. Neurobiol. Learn. Mem. 71: 325-352.

Woodruff-Pak, D.S., Cronholm, J.F., and Sheffield, J.B. 1990. Purkinje cell number related to rate of classical conditioning. Neuroreport 1: $165-168$.

Woodruff-Pak, D.S., Lavond, D.G., Logan, C.G., Steinmetz, J.E., and Thompson, R.F. 1993. Cerebellar cortical lesions and reacquisition in classical conditioning of the nictitating membrane response in rabbits. Brain Res. 608: $67-77$

Wrenn, C.C. and Wiley, R.G. 2001. Lack of effect of moderate Purkinje cell loss on working memory. Neuroscience 107: 433-455.

Yeo, C.H. and Hardiman, M.J. 1992. Cerebellar cortex and eyeblink conditioning: A reexamination. Exp. Brain Res. 88: 623-638.

Yeo, C.H., Hardiman, M.J., and Glickstein, M. 1985. Classical conditioning of the nictitating membrane response of the rabbit. II. Lesions of the cerebellar cortex. Exp. Brain Res. 60: 99-113.

Received December 14, 2005; accepted in revised form March 17, 2006. 


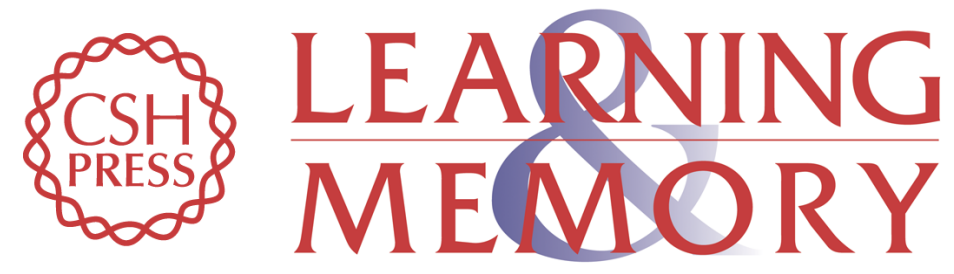

\section{Purkinje cell loss by OX7-saporin impairs acquisition and extinction of eyeblink conditioning}

Brian C. Nolan and John H. Freeman

Learn. Mem. 2006, 13:

Access the most recent version at doi:10.1101//m.168506

References This article cites 52 articles, 18 of which can be accessed free at:

http://learnmem.cshlp.org/content/13/3/359.full.html\#ref-list-1

License

Email Alerting Receive free email alerts when new articles cite this article - sign up in the box at the Service top right corner of the article or click here. 